currents is strongly marked in almost every great thunderstorm, and is precisely analogous to that observed in the centre of a West Indian tornado and of a Chinese typhoon.

When any portion of the atmosphere is ascending it must be because a denser portion is descending, and whenever such motions occur with acceleration the pressure must necessarily be diminished, since the lower strata are not then supporting the whole weight of the superincumbent strata. If their whole weight were supported they would not descend. Thus even a smart shower of rain must directly tend to lower the barometer. [A long glass tube, filled with water, was suspended in a vertical position by a light spiral spring, reaching to the roof of the hall. A number of bullets hung at the top of the water column, attached to the tube by a thread. When the thread was burned, by applying a lamp, the bullets descended in the water, and during their descent the spring contracted so as to raise the whole tube several inches.]

In what I have said to-night I have confined myself mainly to great thunderstorms, and to what is seen and heard by those who are within their sphere of operation. I have said nothing of what is commonly called summerlightning, which is probably, at least in a great many cases, merely the faint effect of a distant thunderstorm, but which has also been observed when the sky appeared tolerably clear, and when it was certain that no thunderstorm of the ordinary kind had occurred within a hundred miles. In such cases it is probable that we see the lightning of a storm which is taking place in the upper strata of the atmosphere, at such a height that the thunder is inaudible, partly on account of the distance, partly on account of the fact that it takes its origin in air of small density.

Nor have I spoken of the aurora, which is obviously connected with atmospheric electricity, but in what precise way remains to be discovered. Various theories have been suggested, but decisive data are wanting. Dr. Balfour Stewart inclines to the belief that great auroras, visible over nearly a whole terrestrial hemisphere, are due to inductive effects of changes in the earth's magnetism. This is not necessarily inconsistent with the opinion that, as ordinary auroras generally occur at times when a considerable change of temperature takes place, they are phenomena due to the condensation of aqueous vapour in far less quantity, but through far greater spaces, than the quantities and spaces involved in ordinary thunderstorms.

In taking leave of you and of my subject I have two remarks to make. First, to call your attention to the fact that the most obscure branches of physics often present matter of interesting reflection for all, and, in consequence, ought not to be left wholly in the hands of professedly scientific men. Secondly, that if the precautions which science points out as, at least in general, sufficient, were recognised by the public as necessary, the element of danger, which in old days encouraged the most debasing of superstitions, would be all but removed from a thunderstorm. Thus the most timid would be able to join their more robust fellow-creatures in watching fearlessly, but still of course with wonder and admiration, one of the most exquisite of the magnificent spectacles which Nature from time to time so lavishly provides.

\section{PHYSICS WITHOUT APPARATUS}

IV.

THE science of heat constitutes one of those depart1 ments of physics in which both the uninitiated beginner and the advanced student can find food for thought. To follow out the theoretical teachings of the science of heat requires a knowledge of abstruse mathematical formulæ; but, on the other hand, a very large

$$
x \text { Continued from p. } 368 \text {. }
$$

proportion of the fundamental facts of experiment upon which the science depends can be illustrated with the simplest means.

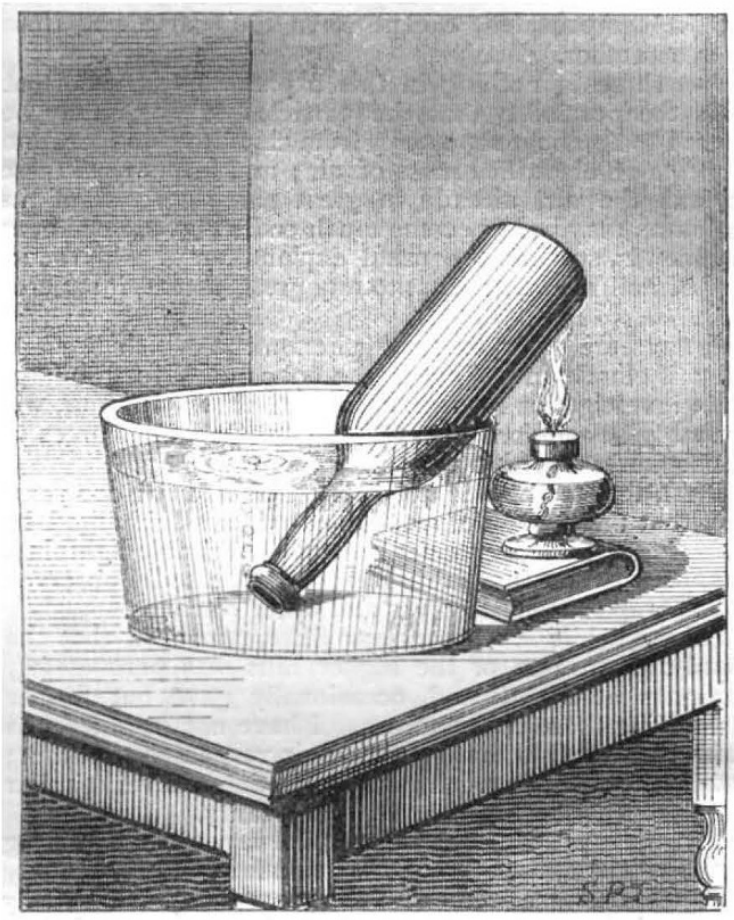

FIG. II.

The property possessed by almost all material bodies of expanding when they are warmed affords us the means

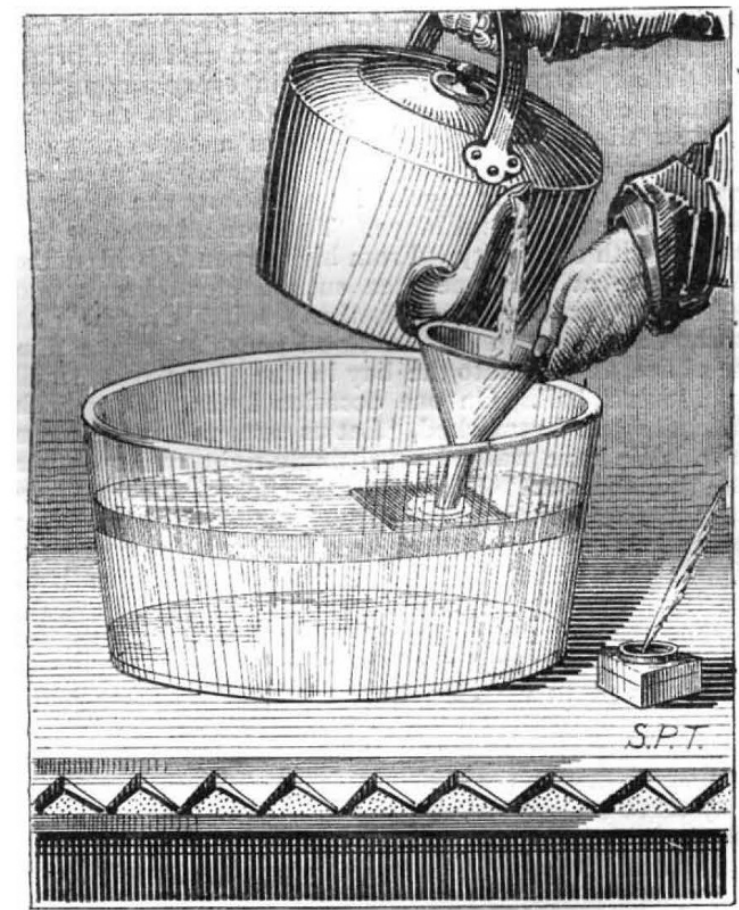

FIG. I2.

of ascertaining the degree to which they are warmed. Thus the expansion of the quicksilver in the bulbs of our 
thermometers shows us the degree of temperature of the surrounding air. Again, the heat imparted to the air within a paper fire-balloon makes it expand and become specifically lighter than the surrounding atmosphere through which it rises. In general it may be asserted that matter, in whichever state it may be-solid, liquid, or gaseous-expands when heat is imparted to it, and contracts when heat is taken from it. Fig. I i illus-

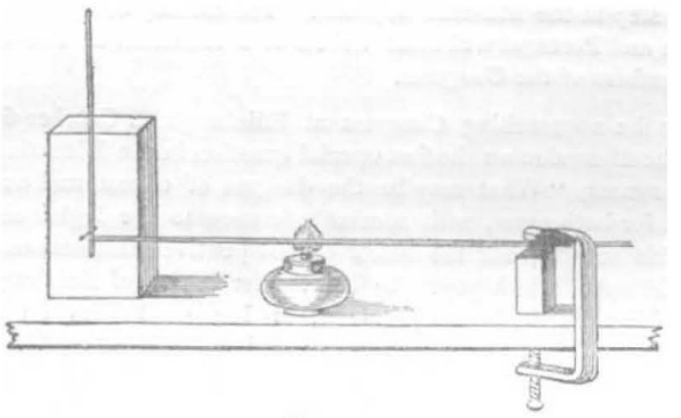

FIG. 13.

trates a very simple manner of showing the expansion of air when heated. An empty wine-bottle is placed with its mouth downwards in a deep dish or jar containing water, the bottom of the bottle projecting over the side of the jar. Heat is then applied by means of a spiritlamp; or, if this is not available, by burning under it a piece of cotton wool soaked in spirits and held on the end of a fork. The glass of the bottle becomes hot-if

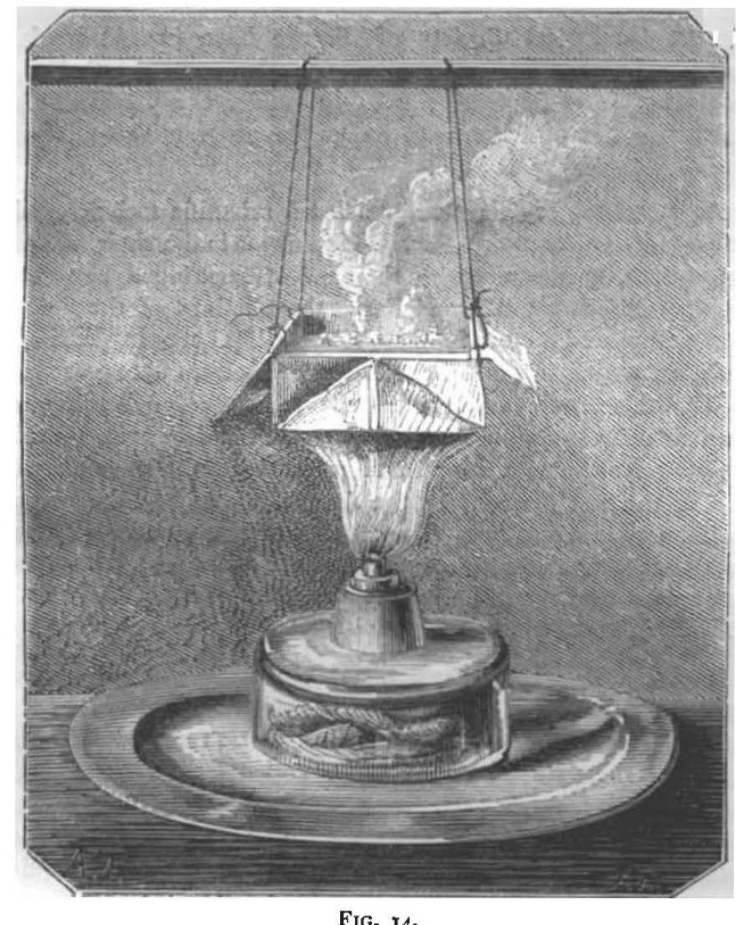

too hot it may crack-and the air inside shares its warmth and begins to expand. There being only a limited space inside the bottle, some of the air will be forced out, and will rise in bubbles through the water. If now the flame be removed, the reverse operation of contraction by cooling may be witnessed, for as the air inside the bottle cools it will occupy a smaller and smaller amount of space, and the water will gradually rise up in the bottle- neck. Of course this is seen better with a bottle of clear glass than with one of a dark or opaque tint.

The contraction of a liquid on cooling can be even more simply shown. Take a common medicine bottle. Warm it gently (by rinsing it out with a little hot water) so that it shall not crack by the sudden heating, and then fill it brimful of boiling water. Leave it to cool ; and in less than half an hour you will find that the water which you poured in to overflowing has shrunk down into the neck of the bottle, having contracted as it cools.

It was mentioned above that the hot air in a fire-balloon raises it, being lighter than the cold air. In the same way hot water will rise through cold, and float on the top of it, being specifically lighter. You may prove this in several ways. Fill a deep jar with water, and then, taking a red-hot poker, plunge about an inch of the tip of it into the surface of the water. Presently the whole of the water at the top will be boiling furiously; but the water at the bottom will be just as cool as before, for the hotter water will not have gone down, but will have

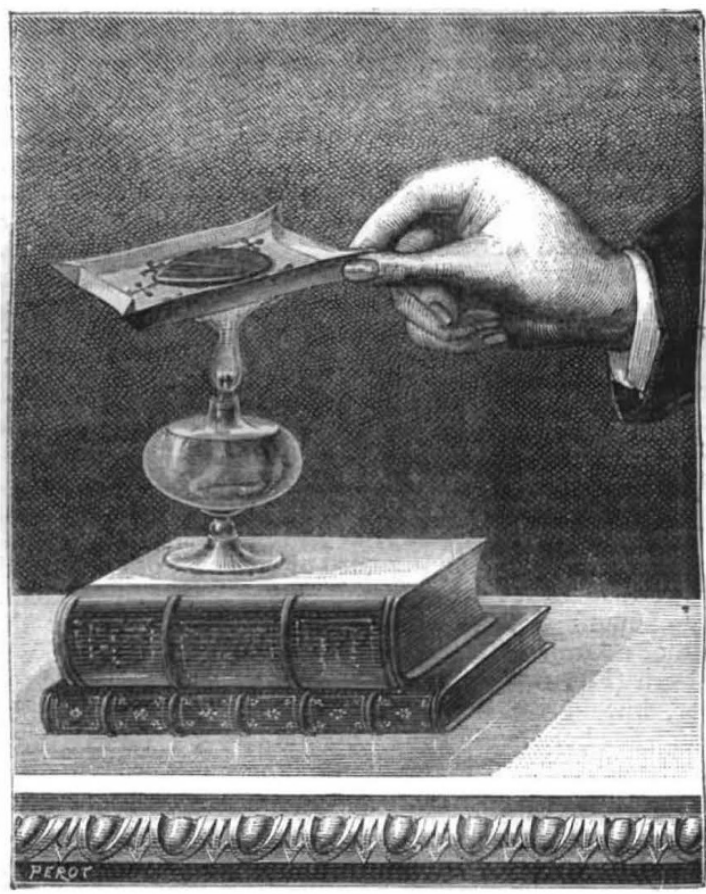

Fis. 15 .

floated at the top, being lighter in consequence of expansion. The same thing can be shown very prettily by the following simple experiment. Fill a wide and deep glass jar-the glass of a parlour-aquarium will do excellentlyto about half its depth with cold water. Provide yourself also with a kettle full of boiling water, a funnel, a bit of wood about three inches square, and with some ink-red ink if possible. Pour into the kettle enough of the ink to colour it with a perceptible tint; this is simply that you may be able to distinguish between the colourless cold water and the coloured hot water which you are going to cause to float at the top. The only difficulty of the experiment is how to pour out the hot water without letting it mix with the cold water. Fig. I 2 shows how you may do this with the help of the things you have got together. The bit of wood (or cardboard) is laid on the water as a float, and you must pour the hot water on to this to break the force of its fall. The funnel will also help to break the fall of the hot water, and will aid you to guide the stream on to the middle of the float. With 
these precautions you need not fear failure, and you will enjoy the spectaclc so seldom seen, though so often actually occurring, of hot water floating on the top of coldt water.

It is almost as easy to demonstrate the fact that solid bodics, such as wood, iron, and glass, expand when heated. $\Lambda$ stcel knitting-necdle, for example, is both longer and thicker when hot than it is when cold. To prove so minute a quantity as the increase in thickness would require very delicite apparatus indeed, but the increasc of length may be rendered visible by the following simple arrangement given by Miss C. Martineau in her capital "Fasy I.cssons in Heat." The knittingncedle must be fixed firmly to the table by a tableclamp (Fig. 13). Against the other extremity rests the end of a straw to serve a's an index or pointer. 'This straw, which should be at least eight or nine inclies long, is transfixed by a pin at abnut a quarter of an inch above the point where it touches the knitting-needle, the pin being sluck into a block of wood or other substantial support. The slightest movement of the end of the steel needle will be rendered apparent by the movement of the straw index.

Another pretty experiment which is easily performed is that of boiling water in a sheet of paper. "Take a piece of paper and fold it up, as schoolboy's do, into a square box without a lid, as shown in Fig. 14. Hang this up to a walking-stick by four threads, and support the stick upon books or other convenient props. Then a lamp or taper must be placed under this dainty cauldron. In a few minutes the water will boil. The only fear is lest the threads should catch fire and let the water spill into the lamp and over the table. The flame must therefore not be too large. A small taper will give a flame quite large cnoughy. The paper does not burn, because it is wet; and even if it resisted the wet it still would not burn through, because the heat imparted to it on one side by the flame would be very rapidly conducted away by the water on the other. Another experiment of a similar nature, but perhaps even more striking, is as follows:-Twist up the edges of a common playing-card or other bit of cardboard, so as to fashion it into a light tray. On this tray place a layer of small shot or bits of lead, and heat it over the flanc of a lamp. The lead will melt, but the card will not burn (Fig. 15). It may be charred a little round the edges, but immediately below the lead it will not be burned, for here again the lcad conducts off the heat on one side as fast as it is supplied on the other. Lastly, we give an experiment which, like the two preceding, proves that a good conducting substance may protect a delicate fabric from burning by conducting away the heat rapidly from it. Iay a piece of muslin quite flat upon a piece of metal. A live coal placed on the muslin will not burn it, for the metal takes away the heat too fast. If the muslin is however laid on a bad conductor, such as a piece of wood, it will not be protected, and the live coal will kinclle the muslin.

\section{(To be continued.)}

\section{NOTES}

THE International Congress of Anthropolory and Prehistoric Archieology, which opens at lisbon on the 19 !h inst., promises to be an interesting onc. On the mornings of the $21 \mathrm{st}, 23 \mathrm{rd}$, $25^{\text {th }}$, and $27^{\text {th }}$, questions relative to Portugal will be diseussedCut Flints of the Tertiary, Characteristics of the Palocolithic or Quatcrnary Agc, the Neolithic Period, Kitchen-mildens, Sepulchral Caves, Agc of Metals, \&c. Among the papers to be read on the afternoons of these days are the following:-M. Arcelin, Antiquity of Man in the Valley of the Saone; M. F. Catailhac, Recent Prehistoric Discoveries in the South of France; $M$. Frnest (hantre, an Exploring Journcy in the Caucasus; M. Ilildebrand, the State of Prehistoric Studies in Sweden; M.
Schaffhausen, Prehistoric Man, \&ec. Several interesting excursions have been arranged for. Perhaps the most important question to be brought before the Congress will be that of the worked stones said to have been found by $M$. C. Ribeiro in the 'Tertiary. The Local Committee have opened numcrous cuttings betwecn Carregado and Cercal, and in that distance of twenty kilometres it is stated that worked stones will be met with at every step in the Miocene deposits. The railway companies of S.jpain and Portugal will issue tickets at a reduction of one-half to members of the Congress.

AT the approaching Congress at Edinburgh on October 6 to 13, the discussion on the first special question in the Educational Department, "What may be the dangers of educational overwork for both sexes, with special reference to the higher class of girls' schools, and the effects of competitive examinations?" will he npened with papers by Dr. Keiller, M.D., of Ldinburgh, and Miss Edith Peachey, M.1)., of I.eeds. l'apers on the secund special question, "IIow far, and under what conditions, ought the teaching of higher subjects in elementary schools to form part of a system of national clucation?" will be contriluted l,y Sir Gerge Campbell, K. C.S.I., and Dr. Rohertson, LL.D. Prof. Lanrie will read a paper on the third special question, "Is it desirable that public secondary schools should be placed under local authorities and be subject to the supervision of the Committee of Council on Education?"

WE are glad to learn that Mr. Mundella intends, during his sojourn on the Continent, to visit some of the principal foreign technical schnols. We have no doubt he will thus get some cnlightenment as to what real technical education means.

THE Geological Society of France have issued circulars announcing that an extraurdinary session will be held at Boulogne, from September 9 to 19 , under the presidency of Prof. Gosselet of Lille, with an ample programme of papers and excursions.

AT a miceting of delegates from local scientific societies, held at Swansea on $\Lambda$ ugust $3 \mathrm{r}, \mathrm{Mr}$. J. Hopkinson in the chair, various suggestions, principally with the vicw of securing a better representation of scientific societies at the meetings of the British Association and a more intimate relationship between provincial societies, were made, and the following resolutions were passed :1. That this Conference recommends that at future mectings of the British Association it is desirable that the delegates from the various scientific societies should meet, with the view of promoting the best interests of the Association and of the several societies rejresented. 2. That Mr. IIopkinson and Mr. Fordham be a committee to carry out the vicws expressed at this conference, and report to the conference of delegates to be held at York in $188 \mathrm{r}$, in accordance with the foregoing resolution.

To judge from the threc volumes of its Bulletin which have been sent us, the Philosophical Society of Washington seems to produce some good work. The Society was founded ten years ago, and the volumes embrace the period from 1871 to 1880 . The late Prof. Joeph IIenry was the first president of the Society; the object of which is stated to be the free exchange of views on scientific subjects and the promotion of scientific inquiry among its members. The following are a few of the papers contained in the volumes before us:- "On the Adopted Value of the Sun's Apparent Diameter," by Prof. F. S. IIolden; "On the 1)ita of the Mississipul," by Frof. Forshey; "On the 7odiacal Light," by Prof. S. Alexander; a detailed report on the unusually brilliant meteor of I)ecember 24,1873 ; a long and elalurate memoir of Prof. Joseph Ilenry, with detailed notices of his varied scientific work; also the addresses he delivered during his presidency; "On the "Prodromus Methodi Mammalium" of Storr," by Mr. Theodore Gill; a curious inquiry on the 